\title{
Hepatocytes, rather than leukocytes reverse DNA damage in vivo induced by whole body $\gamma$-irradiation of mice, as shown by the alkaline comet assay
}

\author{
JUANA PINCHEIRA ${ }^{1}$, PILAR CARRERA $^{2}$, KATHERINE MARCELAIN $^{1}$ \\ and CONSUELO DE LA TORRE ${ }^{3}$ \\ ${ }^{1}$ Programa de Genética Humana, ICBM, Facultad de Medicina, Santiago 7, Chile \\ ${ }^{2}$ Departamento de Biología, Universidad Autónoma de Madrid, Cantoblanco, Madrid, Spain \\ ${ }^{3}$ Centro de Investigaciones Biológicas, CSIC, Madrid, Spain
}

\begin{abstract}
DNA damage repair was assessed in quiescent $\left(\mathrm{G}_{0}\right)$ leukocytes and in hepatocytes of mice, after 1 and 2 hours recovery from a single whole body $\gamma$-irradiation with $0.5,1$ or $2 \mathrm{~Gy}$. Evaluation of single-strand breaks (SSB) and alkali-labile sites together were carried out by a single-cell electrophoresis at $\mathrm{pH}>13.0$ (alkaline comet assay). In non-irradiated (control) mice, the constitutive, endogenous DNA damage (basal) was around 1.5 times higher in leukocytes than in hepatocytes. Irradiation immediately increased SSB frequency in both cell types, in a dose-dependent manner. Two sequential phases took place during the in vivo repair of the radioinduced DNA lesions. The earliest one, present in both hepatocytes and leukocytes, further increased the SSB frequency, making evident the processing of some primary lesions in DNA bases into the SSB repair intermediates. In a second phase, SSB frequency decreased because of their removal. In hepatocytes, such a frequency regressed to the constitutive basal level after 2 hours recovery from either 0.5 or 1 Gy. On the other hand, the SSB repair phase was specifically abrogated in leukocytes, at the doses and recovery times analyzed. Thus, the efficiency of in vivo repair of radio-induced DNA damage in dormant cells (lymphocytes) is quite different from that in hepatocytes whose low proliferation activity accounts only for cell renewal.
\end{abstract}

Key terms: alkaline comet assay, ionizing radiation, hepatocytes, leukocytes, in vivo DNA repair.

\section{INTRODUCTION}

In proliferating cells, repair of DNA damage is under constraints imposed by the autonomous running of the cyclindependent kinases (CDK) cycle. Partial unlinking of DNA repair for such constraints is obtained through checkpoint pathways that, in the presence of DNA damage, transiently block the overcoming of irreversible transitions to a subsequent cycle phase by preventing CDK activation (López-Sáez et al. 1998). In this way, active checkpoints provide additional time for the completion of DNA repair before specific transitions between subsequent cycle phases are allowed (Zhou and Elledge, 2000).
In mammals and plant cells, the DNA damage response is proportional to the proliferative activity (Essers et al, 2006; Hefner et al. 2006). However, it is unknown whether dormant mammalian cells (with no time constraint to repair their DNA) may still display some tissue specificity in this function. For instance, some authors postulate that DNA repair takes place in both hepatocytes (Ono and Okada, 1978) and lymphocytes (Ori et al., 2004), while other authors conclude that DNA damage accumulates in both cell types (Sharma and Yamamoto, 1980; Fenech and Morley, 1985, respectively). To investigate the DNA repair response in quiescent cells, we have studied both the mouse circulating 
leukocytes and hepatocytes. To compare their DNA repair capacities, single cell electrophoresis (comet assay) at a $\mathrm{pH}>13$ was applied at different times after whole mouse $\gamma$-irradiation. This alkaline variant of the comet assay allows the estimation of endogenous and radio-induced single-strand breaks (SSBs), as well as those associated with incomplete excision repair sites. The amount of fragmented DNA migrating to the comet tail is a function of the SSB level present in the nucleus. This technique also detects the fixed set of genomic constitutive alkali-labile sites and, if present, DNADNA and DNA-protein cross-linkings (Tice et al., 2000). The alkaline comet assay is the most sensitive technique for analyzing the kinetics of in vivo DNA repair in nonproliferating cells.

The mechanisms involved in the production of both endogenous and radioinduced DNA fragments are mediated by the formation of SSB. A few of these DNA lesions are directly formed in response to low doses of ionizing radiation. However, most SSB are intermediate lesions produced through the early processing of damaged DNA bases, by the sequential action of enzymes involved in the base or nucleotide excision repair pathways (Christman et al., 2003; Huffman et al., 2005).

In the present work, we found that while hepatocytes were able to repair during 2 hours of recovery, most if not all DNA damage induced by $\gamma$-rays at 0.5 and $1 \mathrm{~Gy}$, leukocytes were unable to. Thus, both cell types differ in kinetics of appearance of the radio-induced DNA lesions, in the maximum level they achieve and, overall, in the rate of their DNA repair.

\section{METHODS}

Two-month-old female mice were used, because nuclear ploidy in liver cells becomes stabilized at this age (Brodsky and Uryvaeva, 1985). Thirty six mice from the NSA CFI strain (2807919A registered number of the UAM Biotherium) were used for the present work. Mice were kept in a $12 \mathrm{~h}$ light/12 $\mathrm{h}$ dark regime, in the fixed conditions earlier described (Carrera et al., 1998).
Irradiation was carried out with a ${ }^{137} \mathrm{Cs}$ source of $1,700 \mathrm{Ci}$ of activity, at a dose rate of $3.7 \mathrm{~Gy} \mathrm{~min}^{-1}$. For each experiment, sets of three mice were irradiated together with 0.5 , 1 or $2 \mathrm{~Gy}$, while another single unirradiated mouse was processed similarly and used as a control. Whole experiments were repeated three times. In each experiment, the manipulation to obtain hepatocytes and leukocytes for each single animal was carried out in parallel by two different persons. It took about $10 \mathrm{~min}$ from the time when the liver and blood samples were obtained from each mouse until cell nuclei were embedded in the second agarose layer (from low melting temperature agarose, InCert, FMC BioProducts Europe, Denmark).

Hepatocytes were obtained according to the procedure previously described. It mainly consists of exposing a fresh section of the liver to a drop of alkaline denaturation solution, and its immediate inclusion in agarose to carry out the microelectrophoresis in alkaline $(\mathrm{pH}>13)$ conditions (Carrera et al. 1998).

Leukocytes were isolated from whole blood (around $250 \mu \mathrm{l}$ ) extracted from the heart. Blood aliquots $(10 \mu \mathrm{l})$ were diluted to one ml with Hank's balanced salt solution (Gibco, USA), $20 \mathrm{mM}$ EDTA pH 7.2, and centrifuged at $15,000 \mathrm{~g}$ for $5 \mathrm{~min}$ at room temperature to collect the resulting pellets. Leukocyte or hepatocyte suspensions (120 $\mu \mathrm{l})$ in $0.5 \%$ low melting point agarose were extended at $35^{\circ} \mathrm{C}$ on the slides covered first by a normal melting point agarose layer (Boehringer-Mannheim, Barcelona, Spain). This second agarose layer was kept at $0^{\circ} \mathrm{C}$ for $10 \mathrm{~min}$. After removing the cover slide, a last $0.5 \%$ normal melting point agarose layer $(85 \mu \mathrm{l})$ was placed on top and flattened by a cover slide. This procedure, as well as lysis, pre-electrophoresis, and staining of DNA was carried out by $4 \mathrm{mg} \mathrm{ml}^{-1}$ ethidium bromide, according to previously described protocols (Tice and Andrews, 1993; Navarrete et al. 1997; Carrera et al., 1998), except that the electrophoresis was carried out at $0.8 \mathrm{~V} \mathrm{~cm}^{-1}$, at $11 \pm 0.5^{\circ} \mathrm{C}$.

An epifluorescence microscope equipped with a 40X objective, a 515-560 nm excitation filter, and a $590 \mathrm{~nm}$ barrier filter 
was used. Comet images were taken by a video camera (Hammamatsu, Photonics k.k., Sunayama-Cho, Japan) that transmitted the images to a computer. In each animal, a minimum of 20 comet images per experimental condition were analyzed by the PC-image VGA program, version 2.10 (Forster-Findlay Ass. Ltd.). The number of DNA lesions or SSB was expressed as a function of the percentage of fragmented DNA present in the tails of the different comet types. The levels for significance of differences among mean values were estimated by applying the Student's t test. The minimal significance was considered at a maximum $P$ value equal to 0.05 .

\section{RESULTS}

In control non-irradiated animals (Fig. 1), the basal DNA damage was around 1.5 times greater in leukocytes than in hepatocytes ( $P$ $<0.01$, Student's t test). DNA damage was recorded as the frequency of DNA fragmented into pieces, as a consequence of the SSB presence, that migrated to the comet tail during electrophoresis. These DNA lesions were endogenous, constitutive ones, produced by aerobic metabolism. Their frequency is considered to be tissue-specific. The recorded DNA lesions also include a fixed number of alkaline-labile sites that characterizes the genome of each species. Both sets of lesions were made evident by the lysis step at $\mathrm{pH}>13$, followed by electrophoresis, under the alkaline comet assay.

The immediate response to radiation (no recovery)

The number of DNA lesions (SSB) was evaluated in hepatocytes and leukocytes of mice exposed to $0.5,1$ or 2 Gy of irradiation doses. The lesions were first recorded at the end of the irradiation period, actually after the $10 \mathrm{~min}$ required for the abbreviated preparatory steps of a fast variant of the alkaline comet assay up to the time the nuclei were included in the second agarose layer (Navarrete et al. 1997). The frequency

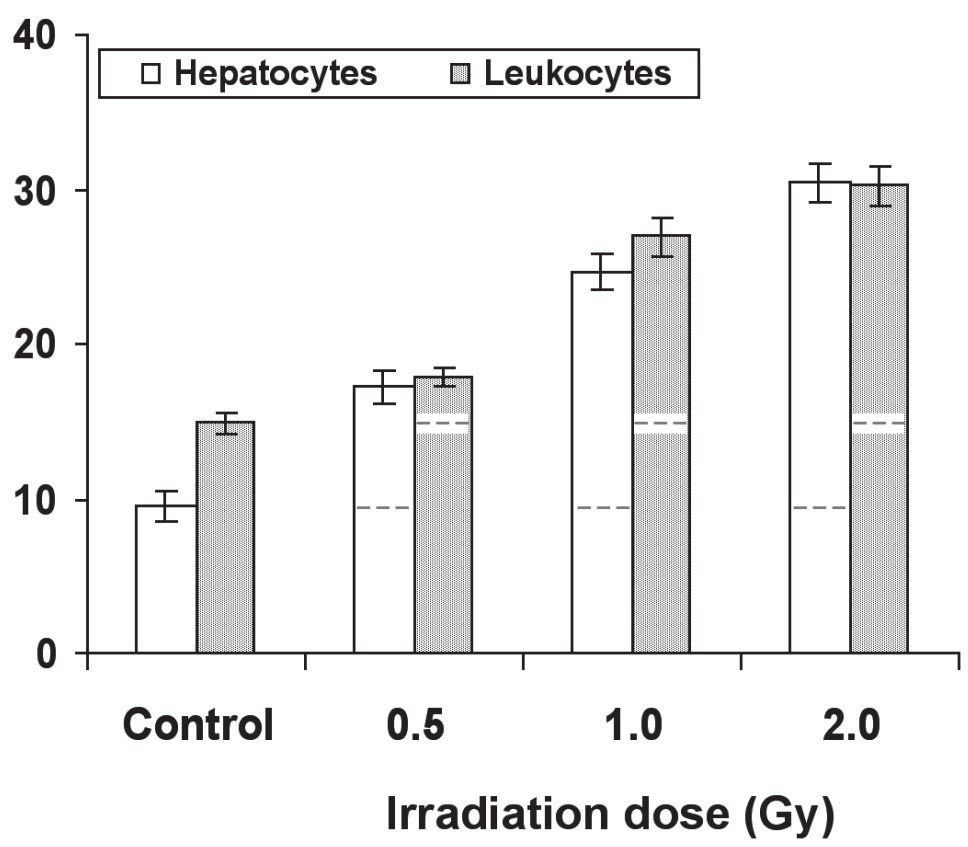

Figure 1: Effect of $\gamma$-rays dose on the frequency of single-stranded breaks (SSB) recorded at the end of irradiation in both hepatocytes and leukocytes by single cell electrophoresis at $\mathrm{pH}>13$. Horizontal lines in each bar represent the endogenous, constitutive SSB level found in the nonirradiated conditions. 
of the SSB responsible for DNA fragmentation, and the migration of the nuclear DNA fragments to the comet tail, after single cell electrophoresis, increased immediately in both cell types after irradiation, in relation to their constitutive damage present before irradiation (Fig. 1). The frequency of SSB recorded immediately after irradiation was a direct function of the radiation dose. Strikingly, for each irradiation condition, the frequencies of SSB achieved at the very end of irradiation were similar in both hepatocytes and leukocytes. When substracting the constitutive DNA damage present in non-irradiated conditions (corresponding to the physiological oxidative damage produced by metabolism plus the alkaline-labile sites unmasked at $\mathrm{pH}>13$ ) from that recorded after irradiation, it was found that the radio-induced SSB were always higher in hepatocytes than in leukocytes (Fig. 1).

In short, the earliest response to irradiation is apparently produced simultaneously to irradiation itself. This fast response is characterized by an increase in SSB, making evident the processing of radio-induced primary DNA lesions that result in a transient accumulation of SSB repair intermediates. Hepatocytes were more efficient than leukocytes in this early processing step.

Effect of recovery time on the frequency of radio-induced $S S B$

SSB levels increased not only during irradiation, but also during recovery, both in hepatocytes and leukocytes (Fig. 2). Cell type specificity was determinant for the response to radio-induced DNA damage after 0,1 and 2 hours of recovery. At the lowest irradiation dose $(0.5$ Gy) the maximum frequency of DNA lesions took place after $1 \mathrm{~h}$ of recovery, both in hepatocytes and leukocytes. Moreover, though after $0 \mathrm{~h}$ recovery time the SSB level was similar in both cell types, the radiationinduced increase in DNA lesions in leukocytes was higher than in hepatocytes (Fig. 2A, B). At 1 or 2 Gy irradiation doses, the maximum SSB recorded in this later cell type was achieved immediately after irradiation, when no recovery (0h) was allowed (Fig. 2A). Conversely, in leukocytes, no variation at the SSB level was recorded in response to 1 or $2 \mathrm{~Gy}$ of irradiation doses, after 1 or $2 \mathrm{~h}$ of recovery (Fig. 2B).

The most obvious divergence between hepatocytes and leukocytes was the difference in their capability to repair radio-induced DNA damage, even though both cell types were quiescent, non-cycling cells. Thus, hepatocytes were able to repair their radioinduced SSB, while leukocytes were unable to repair in the experimental conditions here assayed. In fact, after $2 \mathrm{~h}$ of recovery from the 0.5 or $1 \mathrm{~Gy}$ of irradiation doses, the frequency of SSB regressed to the SSB constitutive level the hepatocytes had before irradiation (Fig. 2A). After 2 Gy irradiation, however, there was only a small but still significant DNA repair activity in the hepatocytes $(\mathrm{P}<0.02$, Student's t test). The corresponding repair rate remained similar throughout the first two hours of recovery.

In open contrast to the situation in hepatocytes, no significant reversal of DNA damage took place in leukocytes (Fig. 2B), at least during the first two $h$ of recovery analyzed, with the exception of a small decrease in the SSB presence that took place $2 \mathrm{~h}$ after irradiation with $0.5 \mathrm{~Gy}$.

Analysis of the population of comets obtained under the different experimental conditions was then carried out. In order to visualize the changes taking place in both cell types -because of the migration of fragmented DNA to their tails as a consequence of the SSB presence- comets were distributed in six different $\mathrm{A}$ to $\mathrm{F}$ classes (Fig. 3). A-type comets possessed tails with less than $12 \%$ of the total nuclear DNA, while the F-type comets with more than $60 \%$ of its nuclear DNA migrated to tails should correspond to apoptotic cells. The other comet classes displayed frequencies of DNA migration to tails between these two values (see legend of Fig. 3). Though the A-E comet types should also include some few apoptotic cells developing earlier steps of the apoptotic programme, they usually remain unknown, due to the technical difficulty in applying specific apoptotic assays. 


\section{Hepatocytes}

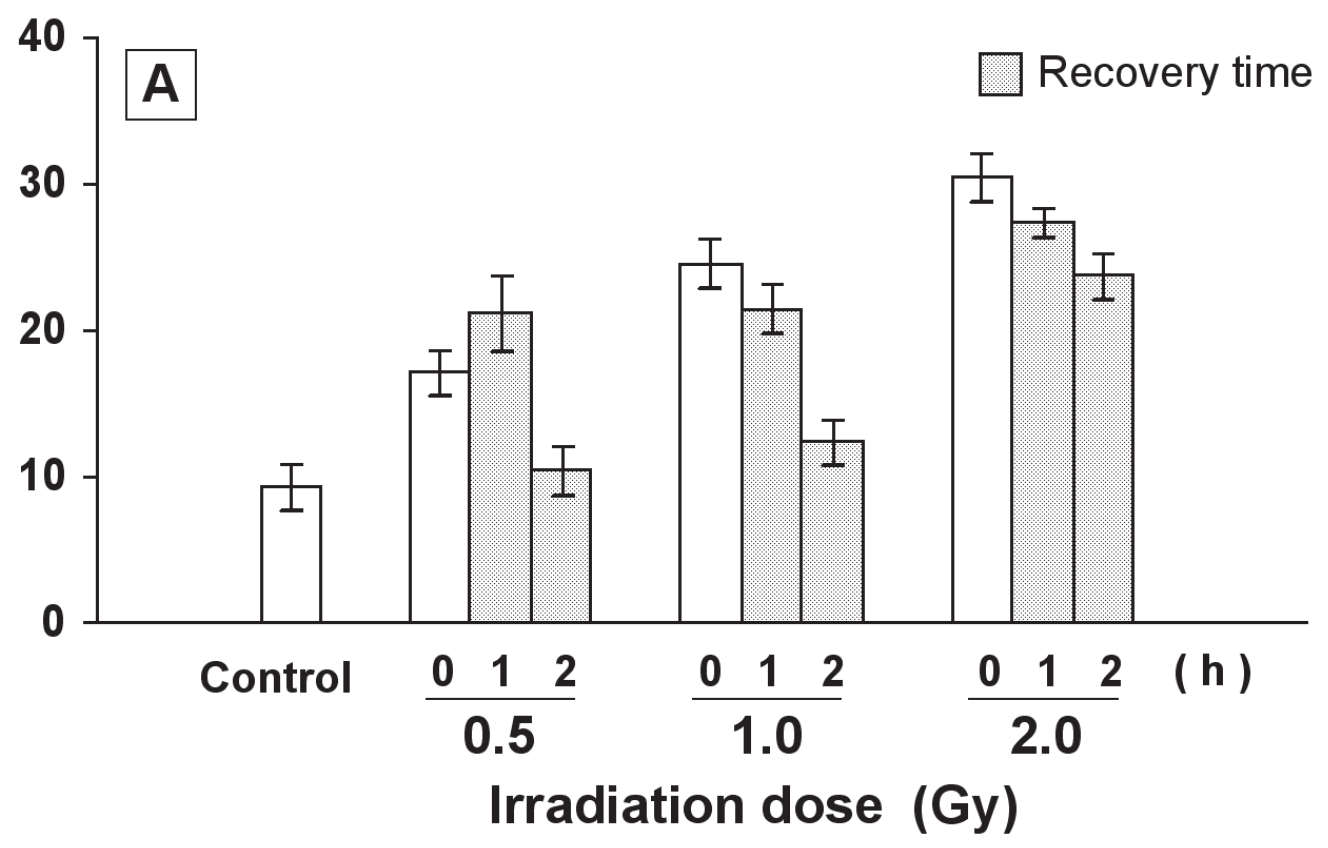

Leukocytes

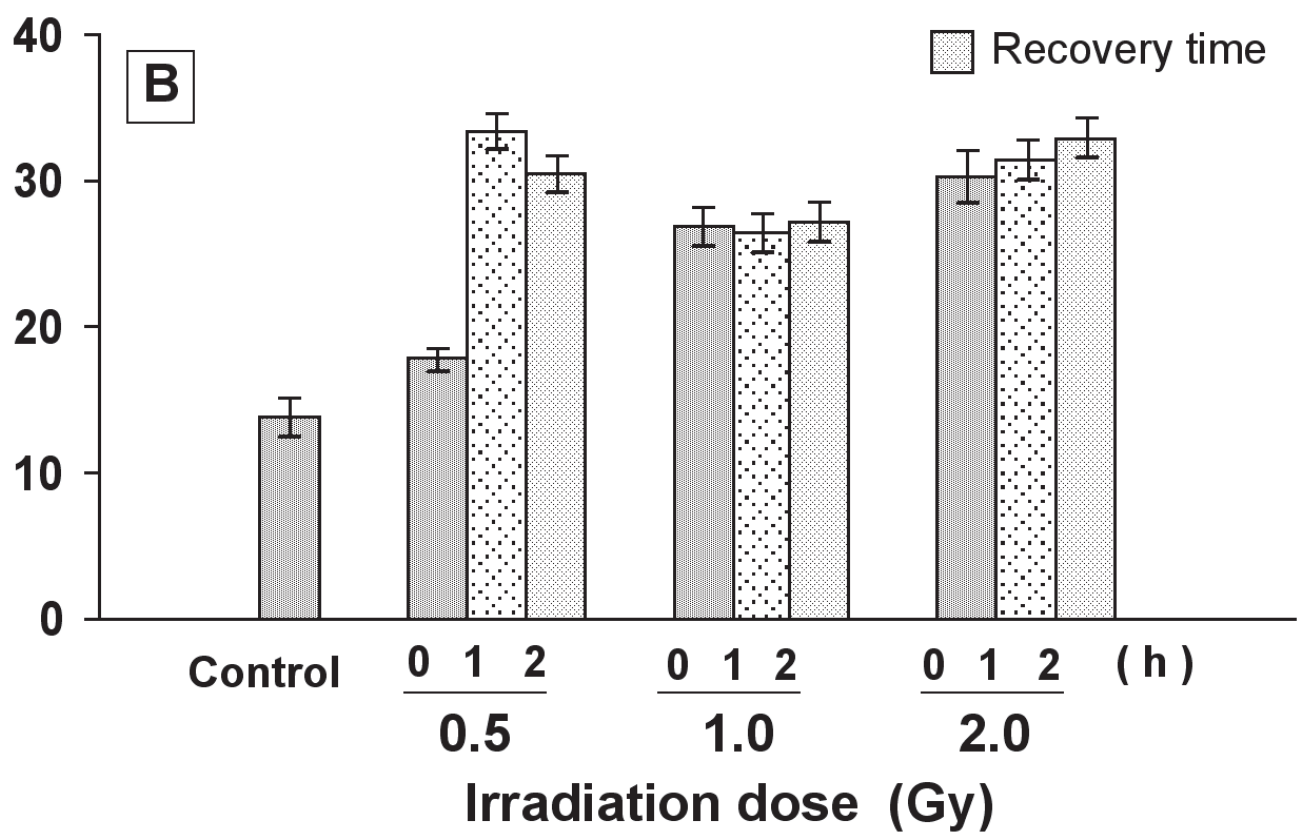

Figure 2: Relationship between the time of recovery from irradiation and the frequency of SSB in hepatocytes and leukocytes, after different irradiation doses. 


\section{Hepatocytes}
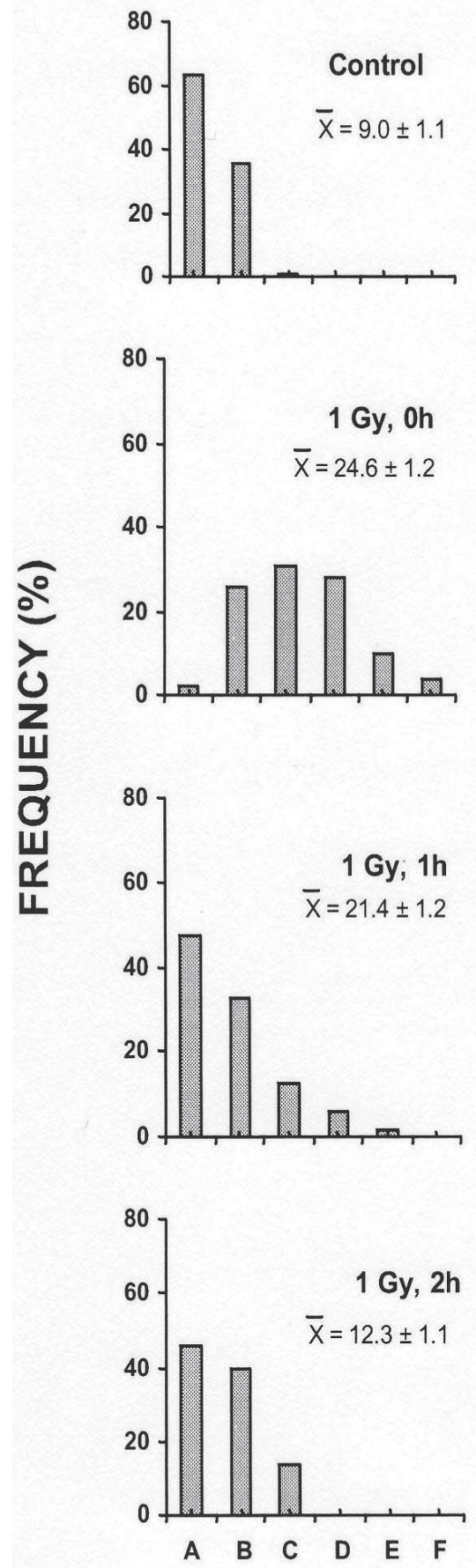

\section{Leukocytes}
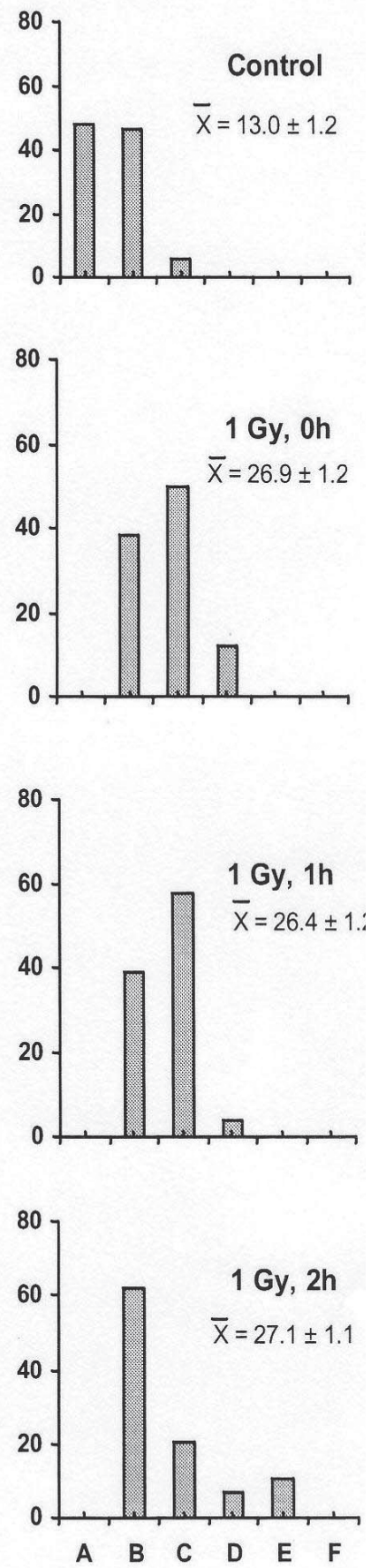

\section{COMET CLASSES}

Figure 3: Frequency of the different types of comet tails observed in response to 1 Gy of $\gamma$ irradiation in both hepatocytes (left column) and leukocytes (right column) of whole body irradiated mice. A-tails correspond to less than $12 \%$ of the nuclear DNA migrated to comet tails; B $=12.1-24 \% ; \mathrm{C}=24.1-36 \% ; \mathrm{D}=36.1-48 \% ; \mathrm{E}=48.1-60$ and $\mathrm{F}>60 \%$, as recorded after alkaline preelectrophoresis followed by electrophoresis. 
Increases in nuclear DNA migration to comet tails secondary to rises in SSB, and their decreases after DNA repair were followed in both hepatocytes and leukocytes. In hepatocytes (Fig. 3), the DNA content migrated to comet tails which first increased, and then decreased during recovery from $1 \mathrm{~Gy}$ of irradiation. If we compare these images to the behaviour of the leukocytes-derived comets (Fig. 3) it is obvious that, even after $2 \mathrm{~h}$ of recovery, leukocytes were unable to regain the comet tail distribution they displayed previous to their irradiation, when only endogenous DNA damage was present (controls). Although the mean frequency of SSB was similar immediately after irradiation and after 1 and $2 \mathrm{~h}$ of recovery, there was some response of the leukocyte population to irradiation, though it lacked any evident trend, because of the heterogeneity of the population itself.

\section{DISCUSSION}

The present results confirm that the repair of radio-induced DNA damage takes place in two different phases. In the earlier one, the primary DNA lesions are processed to single-strand breaks, while in the second one, the SSB are repaired. Thus, there is first an increase and then a decrease in the SSB that the alkaline comet assay detects. The strict time-dependency of the level achieved by the radio-induced DNA lesions (Mozdarani et al. 2007) is fully supported by the present data. As a consequence, the present conclusions should only be valid for the relatively short time of recovery used throughout this study $(2 \mathrm{~h})$.

The rapid increase in SSB recorded when no recovery time from irradiation was allowed might be achieved if the primary radio-induced lesions behave as alkalinelabile sites, with no further processing than their exposure to a high alkaline $\mathrm{pH}$ to make them evident. However, this possibility should be discarded, as after 0.5 Gy irradiation and no recovery, the level of SSB is similar in both cell types (Fig. 2A, B), although hepatocytes displayed less endogenous DNA damage previous to irradiation than leukocytes $(\mathrm{P}<0.01$, Student's t test).

The present observations show the kinetics of the early processing of radioinduced DNA lesions into SSB. These are mostly formed by the action of the enzymes involved in either the base or the nucleotide excision repair pathways (Yang et al. 2006). Considering the basal, constitutive SSB level under control conditions, the efficiency of this early processing resulted in an increase in SSB levels higher in hepatocytes than in leukocytes (Fig. 1). This is consistent with the high metabolic rate displayed by hepatocytes (Jakoby and Ziegler, 1990) which accounts for detoxifying the organism, and for a low but steady rate of renewal of the aged hepatic parenchyma cells. By contrast, these two hepatocyte functions are apparently missing in the terminal circulating leukocyte, although it still repairs endogenous DNA under certain circumstances (Ori et al. 2004).

After the important increase in SSB as intermediate products of the processing of the primary DNA lesions, a second phase starts in which the actual DNA repair takes place. The reversal of SSB was very efficient in hepatocytes. In them, even the basal, constitutive DNA damage level recorded in the non-irradiated mice was again achieved. On the other hand, this DNA repair phase was specifically abrogated in the leukocytes. The present work points out that the expression and function of genes responsible for SSB removal in quiescent cells should be preferentially blamed for the cell typespecific differences in the rate of repair of radio-induced DNA lesions.

SSB are also intermediate processing products of primary oxidative damage, and also of other lesions such as alkylated DNA (Pincheira et al. 2003, in plants). In this case, some of the lesions further develop into mutagenic and lethal double-strand breaks (DSB), when not completely removed (Caldecott, 2007). This scenario, however, may not apply to the endogenous, constitutive DNA damage and to the low doses of irradiation used here, though the present data cannot discard the presence of 
a small number of serious, secondary DSB.

Small differences in the handling of hepatocytes and leukocytes are difficult to evaluate. However, in the non-irradiated mice, the constitutive SSB level was higher in leukocytes than in hepatocytes. Thus, these last cells may be more efficient than leukocytes in diminishing their metabolisminduced SSB, as they are when dealing with the radio-induced DNA lesions.

It is worth pointing out some other aspects of the present results. If we accept that each of the recorded SSB levels results from the differences between their on-going production and the repair of the SSB intermediates, the rate of SSB increase during recovery from 0.5 Gy in hepatocytes might not be dissimilar from that produced in response to $1.0 \mathrm{~Gy}$ (Fig. 2A). Therefore, DNA repair may probably start simultaneous to irradiation or in the subsequent 10 min taken by the cells to be ready for electrophoresis, while SSB are still being formed. This is the case when eliciting the radiation adaptive response to a low irradiation dose previous to a challenging one, in both mouse (MendiolaCruz and Morales-Ramírez, 1999) and other mammalian $\mathrm{G}_{0}$ cells (Cortés et al. 1994).

In conclusion, in whole-body irradiated mice, the efficiency of the in vivo reversal of the SSB processing intermediates of damaged DNA (Huffmann et al. 2005) is strongly cell type-specific in the nonproliferating, dormant cells and in cells proliferating at the low rate required for only tissue renewal. The capability to reverse endogenous or experimentally induced DNA damage seems to be related to the residual metabolic activity that each cell maintains.

\section{ACKNOWLEDGMENTS}

We first thank the late Dr. Matilde $H$. Navarrete, to whom we warmly dedicate the present work, for her enthusiasm and cooperation in the development of the experiments here described. We also thank Mr. J. L Marcilla for his excellent technical assistance, Mr. J. Palacín and Ms. A. Sánchez for access to the Biotherium and to the ${ }^{137} \mathrm{Cs}$ source facilities in the Universidad Autónoma de Madrid. Mice and irradiation facilities were generously provided by the Instituto de Biología Molecular Severo Ochoa, at the Universidad Autónoma de Madrid. This work has been partially supported by the Universidad de Chile-CSIC Agreement (Project 99CLO09), and the Mecesup Postgrado UCH (Project 9903) and also by the Dirección General de Investigación, Ministerio de Educación y Ciencia, Spain (Project BFU2004-03071)

\section{REFERENCES}

BRODSKY VY, URYVAEVA IV (1985) Genome multiplication in growth and development. Biology of polyploid and polytene cells. Developmental and Cell Biology 15. UK: Cambridge University Press

CARRERA P, DE MIGUEL M, LÓPEZ J, DE LA TORRE C, NAVARRETE MH (1998) In vivo response of mouse liver to $\gamma$-radiation assessed by the comet assay. Mutat. Res. 413: 23-31

CHRISTMANN M, TOMICIC MT, ROOS WP, KAINA B (2003) Mechanisms of human DNA repair: an update. Toxicology 193: 3-34

COLDECOTT KW (2007) Mammalian single-strand break repair: mechanisms and links with chromatin. DNA repair (Amst). 6: 443-453

CORTÉS F, DOMÍNGUEZ I, FLORES MJ, PIÑERO J, MATEOS JC (1994) Differences in the adaptive response to radiation damage in $G_{O}$ human lymphocytes conditioned with hydrogen peroxide or low-dose X-rays. Mutat. Res. 311: 157-163

ESSERS J, VERMEULEN W, HOUTSMULLER AB (2006) DNA damage repair: anytime, anywhere? Curr Opin. Cell Biol. 18: 240-246

FENECH M, MORLEY AA (1985) The effect of donor age on spontaneous and induced micronuclei. Mutat. Res. 148: $99-105$

HEFNER E, HUEBNER N, BRITT AB (2006) Tissuespecific regulation of cell-cycle responses to DNA damage in Arabidopsis seedlings. DNA repair (Amst.) 5: $102-110$

HUFFMAN JL, SUNDHEIM O, TAINER JA (2005) DNA base damage recognition and removal: new twists and grooves. Mutat. Res. 577: 55-76

JAKOBY WB, ZIEGLER DM (1990) The enzymes of detoxification. J. Biol. Chem. 2: 321-324

LÓPEZ-SÁEZ JF, DE LA TORRE C, PINCHEIRA J, GIMÉNEZ-MARTÍN G (1998) Cell proliferation and cancer (a review). Histol. Histopathol. 13: 1197-1214

MENDIOLA-CRUZ MT, MORALES-RAMÍREZ P (1999) Damage-repair kinetics and early adaptive response induced by gamma rays in murine leukocytes in vivo. Somat. Cell Mol. Genet. 25: 287-299

MOZDARANI H, NASIRIAN B, HAERI SA (2007) In vivo gamma-rays induced initial DNA damage and the effect of famotidine in mouse leukocytes as assayed by the alkaline comet assay. J Radiat Res (Tokyo) 48: 129-134

NAVARRETE MH, CARRERA P, DE MIGUEL M, DE 
LA TORRE C (1997) A fast comet assay variant for solid tissue cells. Mutat Res 389: 271-277

ONO T, OKADA S (1978) Does the capacity to rejoin radiation-induced DNA breaks decline in senescent mice? Int. J. Radiat. Biol. 33: 403-407

ORI Y, HERMAN M, WEINSTEIN T, CHAGNAC A, ZEVIN D, MILO G, GAFTER U, MALACHI T (2004) Spontaneous DNA repair in human peripheral blood mammalian cells. Biochem. Biophys. Res. Commun. 320: $578-586$

PINCHEIRA J, LÓPEZ-SÁEZ JF, CARRERA P, NAVARRETE MH, DE LA TORRE C (2003) Effect of caffeine on "in vivo" processing of alkylated bases in proliferating plant cells. Cell Biol. Int. 27: 837-843

SHARMA RC, YAMAMOTO 0 (1980) Base modifications in adult animal liver DNA and the similarity to radiation-induced base modification. Biochem. Biophys. Res. Commun. 96: 662-671
TICE RR, ANDREWS PW (1993) Protocol for the application of the alkaline single cell gel (SCG) assay to the detection of DNA damage in mammalian cells. Integrated Research Triangle Park, North Carolina, document \# 27709)

TICE RR, AGURELL E, ANDERSON D, BURLINSON B, HARTMAN A, KOBAYASHI H, MIYAMAE Y, ROJAS E, KYU JC, SASAKI YF (2000) Single cell gel/comet assay: guidelines for in vitro and in vivo genetic toxicology testing. Environ. Mol. Mutagen. 35: 206-221

YANG N, CHAUDHRY MA, WALLACE SS (2006) Base excision repair by hNTHI and hOGGI: a two edged sword in the processing of DNA damage in gammairradiated human cells. DNA Repair (Amst) 5: 43 -51

ZHOU BBS, ELLEDGE SJ (2000) The DNA damage response: putting checkpoints in perspective. Nature 408: 433-439 
